\title{
Networks, Conflict and Collaborative Communities
}

\author{
Dianne Dredge \\ School of Environmental Planning, Griffith University, Australia
}

This paper develops critical understandings of the theoretical and practical implications of local tourism policy networks on collaborative planning. Application of the network concept in tourism has increased in recent years but has largely been focused on the competitive advantages of network organisation for small and medium size tourism enterprises. Critical discussion and development of the theoretical and operational dimensions of networks as a management approach beyond economic development has been limited. It is argued that network theory provides a useful lens for understanding the structures and social interrelations between government, tourism producers and civil society and, as such, has the potential to inform collaborative destination management policy and practice. This paper examines the contributions that networks can make in understanding collaborative planning, and how this knowledge may be able to improve collaborative planning practice.

doi: $10.2167 /$ jost567.0

Keywords: collaborative planning, tourism, networks, conflict, policy communities, community, local government

\section{Introduction}

Critical discussions of sustainable development argue that it is a cultural construct, which is framed, debated and given meaning within the peculiarities of place and time (Jepson, 2001). Despite this ambiguity, sustainable development has become an underpinning tenet for tourism planning and management in many cultures and institutional contexts. Attempts to move the cultural construction of sustainable development from rhetoric to implementation have increasingly called for justice, equity and democracy to be given particular attention in planning and policymaking exercises (Campbell, 1996). That is, through just, equitable and democratic planning and policy, which embrace notions of inclusively, participation and collaboration, it is possible to move closer to the ideal of sustainable development.

It is within the context that, in tourism planning and policymaking literature, there has been increasing attention given to communication and collaboration. Drawing from these theoretical developments, community tourism planning and policymaking is increasingly characterised by dynamic multi-actor interactions, complex power differentials and uneven resource and information exchange between actors and agencies (e.g. Bramwell, 2004; Hall \& Jenkins, 1995; Selin \& Beason, 1991; Truly Sautter \& Leisen, 1999). With respect to tourism planning, two overlapping areas of theoretical writings have emerged as a result of these 
roader trends in social science literature. First, there is a body of theory that examines the sociopolitical context of tourism planning, looking at particular aspects such as power, difference, conflict, influence, knowledge, diverging problem identification and labelling (e.g. Jamal et al., 2002; Reed, 1997). The second broad body of literature is concerned with the critical analysis of collaborative planning practices that seek to channel conflict, emanating from diverse interests, into consensual processes of solution building. Discussions of these practices usually acknowledge that inclusion and exclusion take place and that power differentials play a part in who participates, how engagement takes place and what issues are identified and moved forward. This literature acknowledges that equitable democratic participation is problematic, and distortions in communication can affect the extent to which consensus building is democratic and participatory (e.g. Bramwell \& Lane, 2000; Bramwell \& Sharman, 1999; Jamal \& Getz, 1995, 1999).

In the collaborative planning literature, planning processes are often conceptualised as unproblematic, uni-dimensional, consecutively staged processes. In reality, however, the planning process is frequently characterised by conflict and messy decisionmaking. Powerful groups can form coalitions to dominate the process (Bramwell, 2004). The labelling and categorisation of problems can obscure real issues and serve to divert attention from essential issues (Jamal et al., 2002). Political decisions can be made before data collection is complete, and participants are often faced with the task of legitimising these decisions (e.g. Dredge, 2003). The planning or policy product, while well articulated, justified and defensible, can remain a desktop exercise with little or no implementation and can remain contested within the community despite 'adoption' by local agencies.

In this politicised context of tourism planning and policymaking processes, a fundamental tenet of this paper is that procedural models of collaborative tourism planning alone do not provide adequate guidance for tourism planning and policy development. In addition to the idealistic contribution of normative models, tourism planners also need skills in understanding, anticipating and responding reflectively to complex policy problems, in understanding and mediating differences of opinion and values and in fostering policy innovation and entrepreneurialism (see Forester, 1993, 1999 for a discussion in relation to planning more generally). Jamal et al. (2002: 175) also argue that planners require skills in dialogic interaction and be especially sensitive to the 'philosophical and methodological assumptions that inform their work'. This approach, known as critical pragmatism, needs to be 'pragmatic enough to relate to planners' real problems of getting something done, and 'critical enough to worry about the quality of what in the world gets done and, of course, for whom it gets done' (Forester, 1999: 176, original emphasis). In other words, in addition to the substantive aspects of their work, planners also have to be sensitive to the political nature of their job and pay special attention to the purpose of the planning process. They need to pay careful attention to formal plan and policymaking procedures, and also to the way in which organisational structures and social interrelations might impact upon the substantive issues contained within the plan or policy. Deep understandings of the messiness and complexity of the tourism planning process, the effects of power differentials and interest struc- 
tures that operate over time and across space are critical for the development of the social and intellectual capital of the destination.

On this basis, there is a need to develop tools and methods that enhance understandings of complex government-business-civil society relations, the political nature of planning and policymaking and the inequities existing within such practices. Understanding and managing these dimensions can empower tourism planners as active, entrepreneurial policy agents. The paper posits that network theory can be used as a lens to understand these social interrelations through which council-business-civil society relationships can be better managed. In other words, network theory adds an explanatory dimension to normative planning and policymaking processes. The contributions of network theory need to be further explored if we are to address the criticisms of collaborative planning theory as being somewhat idealistic and naive to the political context in which planning and policymaking takes place (e.g. Flyvbjerg, 1998; Healey, 1997).

This paper focuses on two main objectives:

(1) To identify the potential contributions of network theory to collaborative tourism planning theory through a critical evaluation of the strengths and weaknesses of both streams of literature.

(2) To examine how network theory might improve collaborative tourism planning in practice.

In addressing these objectives, the paper examines a tourism planning case study in Redland Shire, Queensland, Australia. While this exercise sought to be collaborative, the rich and varied social relations between networks operating at different scales across the local government area contributed to a final plan that has not been fully legitimised by Council (the commissioning agency) or the numerous other agencies and individuals involved. Contrary to some of the collaborative tourism planning literature, the case study is not presented as an exemplary collaborative planning exercise. Instead, it is useful because it illustrates the way in which networks operate in and around collaborative tourism planning processes to empower some issues and agents and disempower others. In this way, networks are important for the development of collaborative planning processes that acknowledge power differentials, conflict and difference.

The paper is divided into four main parts. The first part explores network theory, identifying the potential strengths and weaknesses of this body of theory. The second part explores the value of network theory to collaborative planning theory and practice. The third part presents the case study before the final part provides a reflective discussion on how network theory might be used to improve collaborative planning theory and practice.

\section{Origin and Relevance of Network Theory}

This part of the paper explores the origins of policy network theory and how it might be relevant to the theory and practice of tourism planning and policymaking. In its broadest interpretation, network theory is concerned with relationships between government, business and civil society and how these relationships shape issue identification, communication, resource sharing and 
collective action (Marsh, 1998a). It finds its modern origins in the 'whirlpools of interest' that attracted the attention of sociologists working in economic and political spheres in the 1930s (see e.g. Parsons, 1995), and was, no doubt, influenced by the dominance of systems theory at that time. Among other contributions, systems theory stimulated interest in how systems and sub-systems of social relations operating horizontally and vertically, within and across policy domains, influence policymaking. Over the last decades, the concept of policy networks has become a powerful metaphor that reflects the richness of interest structures, the contestation of agendas, issues, values and approaches, the uneven character of organisation and the reflexivity of business-government relationships (Atkinson \& Coleman, 1992: 155).

Under the influence of these broad developments in the social sciences, it was not until the 1970s that the concept entered into policy analysis literature, with both American and British researchers claiming formative development (for a full discussion of British and American antecedents see Marsh, 1998a; Rhodes, 1997; Richardson, 2000). This point of argument aside, the origin of the network concept has widely been attributed to Heclo's (1978) 'iron triangle'. In this development, and influenced by the particular political context of the United States, the notion of 'sub-government' was used to denote the close relationships between interest groups, congressional committees and government agencies (Howlett \& Ramesh, 1995). 'Iron triangle' was the metaphor used to denote the tight control these three groups had over policymaking, which effectively minimised the influence of outsiders (Burstein, 1991). Later, Heclo (1978) developed 'issue networks' in response to the observation that iron triangles were not all-powerful and that their influence on policymaking varied (Howlett \& Ramesh, 1995). Issue networks were intended to reflect a more open and less organised set of relations between policy actors, where levels of participation and interest changed over time and across different policy issues (Burstein,1991). Later, Sabatier (1987, 1988; Sabatier \& Jenkins-Smith, 1993) developed the advocacy coalition framework. This framework was based on the idea that policy actors form alliances around a common set of core beliefs and goals, often as a result of their knowledge of a policy problem and similar worldviews. These coalitions of actors seek to achieve common goals by competing against other advocacy coalitions to manipulate policy formulation over time. In Sabatier's conception, these coalitions were relatively stable over time, held together by common, ongoing interests. However, their success is dependent upon a range of internal factors (e.g. resources, expertise, leadership and authority) and external factors (e.g. problem persistence, public opinion and economic conditions).

In the tourism literature, over the last five years there has been a small but steady increase in the use of network theory for understanding certain aspects of destination development and management. While applications have varied widely, and it is perhaps too early to draw conclusive insights, two main streams of research have emerged. Firstly, there is a growing body of research that examines the strategic network organisation of firms, and how the nature of social transactions and resource exchange influence product innovation, complementarities and economic efficiencies (e.g. Braun, 2002; Dale, 2003; Halme \& Fadeeva, 2000; Pavlovich, 2001a; Tinsley \& Lynch, 2001; Tremblay, 1998). This body of literature is derived from interorganisational literature and is highly 
focused on the structure and relational capacity of networks to produce commercial complementarity, synergy and profitability.

The second stream of research is devoted to investigating the networked nature of public-private interest structures and the influence of these networks on tourism policymaking and implementation (e.g. Dredge, 2003; Pforr, 2002; Tyler \& Dinan, 2001). This stream is less well developed with two main reasons proposed. Firstly, theoretical development of policy networks draws from policy analysis literature in which North American and British contributions have spent more time debating theoretical definitions and concepts instead of application and theory building (see e.g. Howlett \& Ramesh, 1995; Rhodes, 1997, for a detailed explanation of these debates). Applications of network theory have tended to examine networks operating at higher levels of government (e.g. between central and local governments in the UK or between national government and business interests in the US) with few case studies that examine local networks. Secondly, in the current research climate, dominated by neo-liberal economic management ideals, research focused around business partnerships and networks motivated by profitability, competitiveness and economic efficiencies is a 'sexier' theme of investigation, and thus, has attracted greater research interest.

These two streams of network research, inter-organisational business networks and public-private policy networks, are not unrelated. Innovative, catalytic producer networks require policy and regulatory environments that are flexible and capable of timely response. The nature of linkages between government and industry is important in ensuring timely and well-targeted policy responses (Commonwealth Department of Industry, 2003: 87). However, this paper argues that, in both streams of research, relationships between business, government and civil society in shaping network structures and relations have not received adequate attention. Moreover, the implications of networks for tourism planning and the development of destination management capabilities (e.g. innovation and policy entrepreneurialism), have not received the attention they deserve. Partial support for this position comes from Hall (1999) who, in a discussion of partnerships and collaboration, argues for more focused attention on the role of the state and raises issue with the way in which current partnership approaches deliver more so on narrow sectoral interests and less so on broader public interests (p. 285). Bringing the state and civil society into focus, and specifically the role of the state in promoting and protecting certain public interests, can help focus attention on the inclusionary and exclusionary effects of policymaking and how democracy is interpreted and given meaning.

Greater attention upon the role of the state and its relationships with producer groups and civil society is needed in order to balance the current market-driven focus of networks and to ensure that networks also deliver on community wellbeing in its broadest, not just economic, sense. Yet network theory is still underdeveloped. Most existing tourism network research argues that networks offer a useful analytical tool for understanding the structural characteristics and social interrelations that shape destination planning and management (Dredge, 2003; Pavlovich, 2001b; Tyler \& Dinan, 2001). However, caution is still needed. Most of the literature uses networks to describe and explain policy outcomes in retrospect. There is a need to develop network theory as a lens for under- 
standing the social interrelations of policymaking and to harness management opportunities that come from these in-depth, reflective understandings.

However, one should not blindly adopt networks without understanding the strengths and weakness associated with this emergent theory. Some claim that networks are not a panacea for explaining destination planning and policymaking, and well-founded criticisms are emerging in the wider body of policy analysis and organisational studies (e.g. Borzel, 1998; Klijn, 1996; Marsh, 1998b; Peters, 1998). For tourism studies, it is now time to critically assess the emergent literature and to establish a research agenda that assists in developing a corpus of knowledge about tourism policy networks that can be used to bring balanced understandings of state-business-civil society relationships, and to focus the state's role in managing and improving planning and policy outcomes. This knowledge should be focused not just on describing and explaining policy shifts in retrospect, but should develop reflexive understandings about different network configurations and characteristics. This reflexive knowledge can be used to better manage tourism networks and improve planning and policy outcomes beyond what would be expected if networks were left to their own evolution. This agenda should address both theoretical and empirical dimensions of networks and avoid fragmentation (a danger in the case study approach) and poor theoretical development; criticisms that have been applied to the broader body of tourism policy studies (e.g. Hall \& Jenkins, 1995).

\section{Contributions and criticisms of networks}

Within the broader literature on policy networks two main criticisms are emerging. It is timely to reflect on whether these criticisms are applicable to tourism, and what they mean for the tourism policy research agenda. Firstly, networks have been criticised because they are difficult to define operationally. Networks transcend private-public sector boundaries and extend vertically and horizontally within and across policy domains. Network boundaries can be open or closed, operate across diverse spaces and over time. Applied network research is, therefore, made more difficult because networks are difficult to define in an operational sense. This in turn is further exacerbated by a lack of agreement over terminology (e.g. see Howlett \& Ramesh, 1995; Marsh, 1998b). The prevailing view, held by British researchers, is to differentiate between the broader issue network comprising all actors and agencies with an interest in a policy domain and a tighter, more connected policy community made up of active individuals and agencies (see Figure 1). Marsh and Rhodes (1992) argue that issue networks and policy communities exist on a continuum; that issue networks are loose configurations of actors with a broad interest (formalised or not) in a policy problem and policy communities have a tighter structure, closer relationships and defined membership. In this view, policy networks are treated as a generic term denoting sets of social relations.

Figure 1 illustrates the relationship between policy network and policy communities. This figure illustrates the dynamic movement of individuals and agencies in and out of active participation and the relationship to other related and overlapping networks. In relation to tourism destinations, overlapping networks might include chambers of commerce, community and environmental groups. Depending upon current issues in the local network, a regional network 


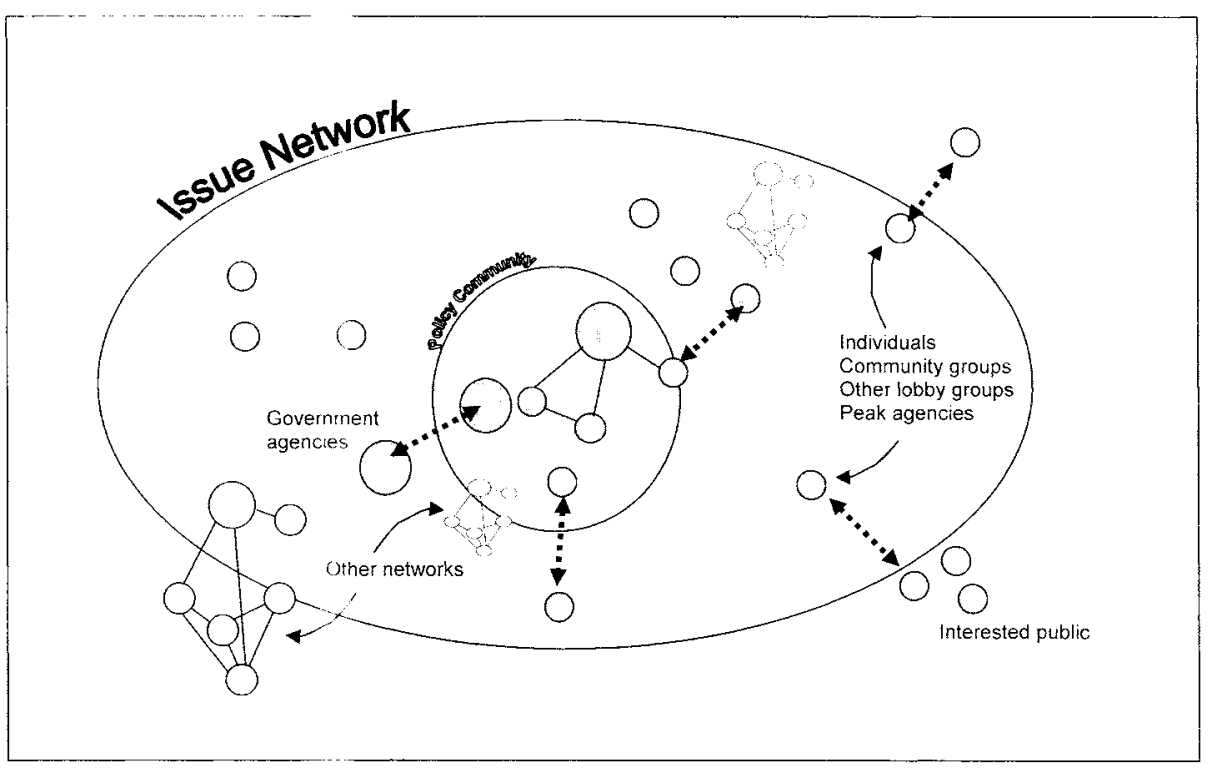

Figure 1 Issue networks and policy communities Adapted from Pal (1997)

(e.g. RTO) might remain in the interested policy network but will move into the active community if a particular issue activates their concern.

Networks exist at macro levels, meso levels and micro levels. They overlap and interlock. They operate independently and interdependently. The intensity of network interrelations change according to a variety of factors such as the spatial scale the network traverses, the nature of the issues, the political salience of the issue and so on. So, policy networks exist from loose to very tight configurations over different scales; they can be complementary, conflictual, independent or interdependent. Socio-historical foundations condition networks to the point that it is impossible to define networks without reference to their context. For this reason, network definition is dependent upon empirical application and context. As will be discussed later, for those seeking to develop overarching definitions and normative theories of networks, this fluidity and contextualisation is of concern (e.g. Dowding, 1995). For others, the fact that networks emerge out of the investigation and are not artificially bounded is a compelling advantage (e.g. Marsh, 1998b).

Secondly, it has been argued that network theory is a useful heuristic tool that serves as an organising framework for understanding policymaking; however theoretical development is weak (Borzel, 1998; Klijn et al., 1995). Dowding (1995) argues that the characteristics of the components of the network (e.g. membership, rules of conduct, relational ties) become the agents of explanation and not the network characteristics themselves (e.g. open networks, closed networks). In his view, researchers must continue to rely on explanations drawn from diverse literature on, for example, power, leadership and the policy cycle, leading to the conclusion that networks, as a theoretical explanation, fail. Klijn (1996) and 
others acknowledge the lack of theoretical development characterising networks, but argue that networks are not a theoretical dead end. More work is needed. Greater understandings of the potential theoretical and practical contributions of networks can be gained from considering how network theory intersects with the increasingly important planning ideal of collaborative planning.

\section{Collaborative Planning, Networks and Tourism}

Collaborative planning is an ideal that has been derived most particularly from interpreting the works of German philosopher Jërgen Habermas (1984, 1987). It is not the aim of this paper to interrogate the philosophical origins of collaborative planning, (see e.g. Flyvbjery, 1998); however, it is important to acknowledge the powerful ideas contained within Habermas's notion of 'communicative action' (1984). Communicative action is based on the idea that, unconstrained, discourses between actors can produce consensus that is built up through shared understanding and tradeoffs made on the basis of greater understanding of alternative points of view. Fischer and Forester (1993) were first to translate this communicative turn into planning and policy, reiterating the value of argumentation, dialogue and collaboration in finding solutions for complex planning problems. Planners, especially those working within bureaucratic frameworks and feeling frustrated by the inadequacies of traditional bureaucratic planning and policymaking, were quick to adopt the collaborative approach. Moreover, collaborative planning sat well within the increasing adoption of neo-liberal public management philosophies where governments were increasingly downsizing, outsourcing and offsetting their responsibilities.

These interpretations of collaborative planning have been criticised as inadequate in their understandings of how power is constituted and mediated within an inherently political world. Flyvberg (1998) suggests that collaborative planning has been simplified and that an idealised version of democracy underpins communicative action and that collaborative planning does not always achieve just, equitable and democratic planning outcomes. Flyvbjerg bases his position on the works of Michel Foucault. Foucault sees the world as being inherently political and Habermas's work as inadequate in its understandings of the way that power is constituted in society (Foucault, 1980). Foucault holds no idealised vision of democracy as a rational process of negotiation and compromise. Actors can be included or excluded, speech is never completely open or free of influence, and people don't always act for the rational good. In essence, communicative action is an ideal that doesn't reflect everyday politics (Ryan, 1992, in Flyvbjerg, 1998). Flyvbjerg (1998) argues that a healthy civil society is one that allows conflict, encourages freedom of speech and the questioning of government actions and public policy processes. In these circumstances, contestation can lead to creativity, policy entrepreneurialism, innovation and learning.

Within the tourism planning literature, collaborative planning and partnership building has received increasing attention. Bill Bramwell and his collaborators (e.g. Bramwell, 2004; Bramwell \& Lane, 2000; Bramwell \& Sharman, 1999; Medieros de Araujo \& Bramwell, 2002) and Jamal and Getz (1995, 1999) are among those influenced by this turn in planning theory. These authors highlight the importance of involving diverse stakeholders in participatory processes 
of consensus-building and partnership formation (Bramwell \& Lane, 2000: 1) and acknowledge the benefits of collaborative planning, especially in terms of promoting collective learning, capacity-building, discussion, and mutual learning. They see adversarial conflict as 'wasteful' (Bramwell \& Sharman, 1999: 392) but point to the potential advantages of conflict where it raises public awareness and understanding (Lovelock, 2002).

This presence of difference, tension and conflict in tourism planning and policymaking has given rise to a genus of tourism planning and policy research that critically explores processes of collaboration and partnership building. Past research on collaborative planning and partnership building suggests that power differentials play a significant role in shaping the collaborative process, and the extent of ownership over the solutions that emerge. Underpinning this observation are questions about the role of power and conflict, and whether or not just, equitable and democratic outcomes are actually achieved in some collaborative planning exercises. On this basis, further research into the way power is manifested and conflict is managed in collaborative planning is useful (Bramwell, 2004; Lovelock, 2002).

Booher and Innes (2002) idealise networks as an extension of their conception of collaborative planning, arguing that networks of power can emerge from the authentic consensus-building dialogue of collaborative planning. The following case study suggests that Booher and Innes (2002) present an idealised version of communicative action and that the reverse can also be true. That is, networks of power can also emerge from a breakdown in communication and contestations between networks can also produce a range of positive outcomes including greater tolerance of difference, innovation and learning.

This paper raises concern over uncritical adoption of collaborative and communicative planning ideals and the usurping of networks as a collaborative tool within the mantra. McGuirk (2000) and Flyvbjerg (1998) argue that communicative action fails to recognise that diversity and difference exist and cannot be negotiated away. Policy actors will only negotiate on those issues upon which they think consensus can be reached, so agreed solutions are relatively superficial and relationships between government and civil society can be weakened as a result. Flyvbjerg (1998: 210) makes the case that 'we need to deal with the problems of exclusion, difference, diversity and the politics of identity' as a way of empowering and strengthening a democratic civil society. Bramwell highlights concerns that collaborative planning ideals can also be exclusionary and undemocratic, and that an important arena for future tourism research is to evaluate how specific approaches to tourism planning affect the final distribution of tourism costs and benefits (Bramwell, 2004: 551).

From these critical questions of the role of consensus and conflict in planning and policy, networks have started to emerge as an alternative lens that injects a sort of 'reality' into communicative action (e.g. McGuirk, 2000). Collaborative, consensual planning takes place when policy communities, made up of actors with temporarily similar worldviews and commitment to common goals, find a common platform or purpose for negotiation and compromise. However, 'collaborative' planning only takes place on those issues on which actors are willing to negotiate and compromise. Boundaries of tension, conflict and instability can exist between policy communities that are not willing or unable to negotiate, 
giving rise to spaces of policy inclusion and exclusion, and windows of collaboration and non-collaboration. Given the fluidity and reflective nature of planning discourses, these relationships are dynamic. Herein lies an important contribution of network theory to collaborative planning. Better understandings of the way in which networks interrelate to influence the planning process can lead to better process design, increased quality of collaboration, learning and innovation. Figure 2 summarises these relationships.

The following case study explores how interrelations between policy communities influence tourism planning process. Comments are also made about some of the underlying assumptions on which collaborative planning is built, including inclusivity, democracy and consensus. The goal is not to debase communicative action approaches, but to make more critical and reflective comment about the values on which this paradigm rests and to offer an improved understanding of communicative action for researchers interested in understanding the dynamics of destination planning, policymaking and management. In particular, collaborative planning is silent on matters of inclusion and exclusion and the effects of conflict and diversity. Based on this discussion, a Foucauldian inspired interpretation planning and policymaking is adopted in this paper, which emphasises the way in which power and meaning are constituted in the political discourses of tourism policymaking. In this view, power exists in the individual. The ceding of power, totally or partially, allows political power to be established and power differentials to emerge (Foucault, 1976: 19). In the network view, constellations of power within tourism policymaking give rise to boundaries of difference, conflict and instability. The discourses between these constellations of interests are not necessarily wasteful but can also be sites of learning, creativity and innovation.

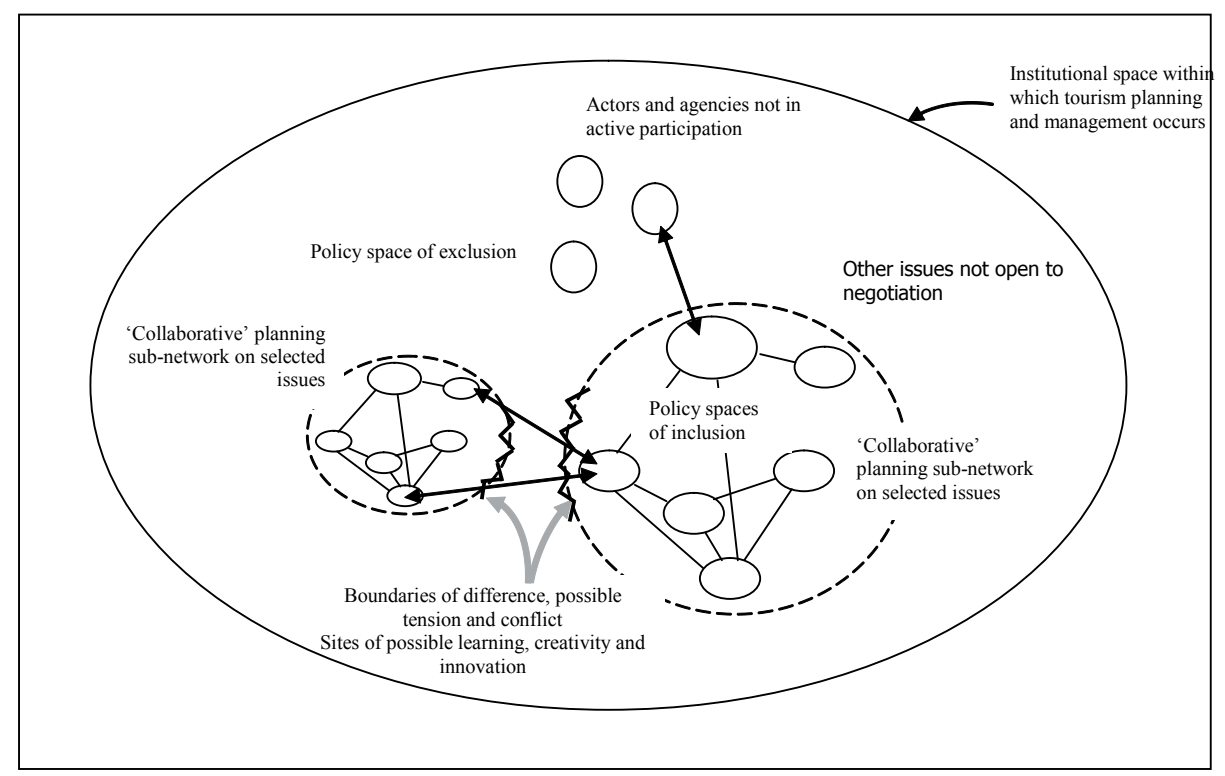

Figure 2 Issue networks and collaborative policy spaces 


\section{Case Study}

\section{Research approach}

Based on the above discussion of network theory and collaborative planning theory, this case study examines the way in which network interrelations influence tourism planning processes. It differs from other network research that focuses on the characteristics of the networks and the influence of particular networks on collaborative planning processes. In other words, the research approach here recognises that multiple networks exist and that relationships between these networks have a significant effect upon the extent to which collaboration takes place, and how concepts such as democracy, justice and equity are given meaning in the planning process. Accordingly, this study focuses on the influence of relational ties between networks upon collaborative planning. The case study is used to explore in practice whether or not the factors discussed above and depicted in Figure 2 exist and to what extent they might influence the planning process. These factors include:

- issue networks and policy communities - the characteristics of issue networks and policy communities (e.g. extent of overlap in issues and goals, overlaps in membership, perceived legitimacy);

- institutional space - the extent to which the planning process is seen to occur within a legitimate institutional space and the congruency between interpretations of this institutional space by different networks;

- inclusion and exclusion - the influence of networks on creating and maintaining policy spaces of inclusion and/or exclusion;

- collaboration and non-collaboration - the influence of networks on spaces of collaboration and non-collaboration; and

- boundaries of difference - the nature of boundaries of difference, and whether these are sites of conflict and tension or sites of learning, innovation and creativity.

The research was conducted over a 12 month period from January 2003 when Redland Shire Council was involved in the preparation of a number of interrelated planning studies. At the time the Council was preparing a new planning scheme, a visioning study for Stradbroke Island and a Sustainable Tourism Strategy for the Shire. These simultaneous planning processes stimulated widespread community interest and served to galvanise certain interest groups across the Shire. However, interest groups worked within the different planning spheres associated with different planning studies being undertaken. Overlap on issues was apparent to the researchers yet the interest groups tended not to become involved across the imagined boundaries created by the different planning studies. It was this observation that attracted the researchers to undertake this particular case study. Multiple sources of data were used to build a rich contextualised history of the destination, key individuals and agencies. Primary data sources included semi-structured interviews with Council officers and local tourism organisation representatives. The researcher also attended community meetings and organised workshops as a participant observer, from which detailed notes were made. Informal networking with tourism operators and community representatives was also undertaken during these meetings and 
workshops. This informal information contact was principally used to corroborate evidence. Secondary data included historical research of local newspaper databases and council documents. A highly structured and comprehensive community engagement strategy was being undertaken by consultants for the purpose of the Tourism Strategy and information obtained from this process was also drawn upon for this research. For further discussion of the issues and approaches to researching networks see Dredge (2006).

\section{Case study background}

Redland Shire (pop. 118,000), located to the south-east of Brisbane, is a local authority which takes in significant coastal areas and seven southern Moreton Bay islands. Up until the late 1970s, Redland Shire was the 'salad bowl' of Brisbane, referring to its rich agricultural lands and predominance of market gardens. More recently it has become a dormitory subregion of the south-east Queensland conurbation with a large proportion of residents travelling outside the local government area for work. The Shire has also been subject to considerable growth in the service economy with close to half the resident labour force employed in wholesale and retail trade, property and business services, health and community services and cultural and recreation services (Shepherd \& Liew, 2003). The Shire includes North Stradbroke Island (NSI), one of the largest and most spectacular tourism assets of Moreton Bay. However, tourism activity in the Shire remains relatively small. Reliable estimates of visitation are unavailable at this level. It is estimated however, that Redland Shire receives only a small proportion of the 4.9 million domestic and international visitors and 22 million visitor nights that the Brisbane Region receives each year. Moreover, in a region of over 1.8 million inhabitants, Redland Shire receives about $4 \%$ of total daytrips (ATS Consulting Services, 2003). There is also an acute seasonality of visitation, illustrated by close to $100 \%$ occupancy in commercial accommodation on North Stradbroke Island during summer school holidays but an average annual occupancy of around $29 \%$.

Against this background, an important local economic development concern of the Council was to grow Redland's market share, generate employment opportunities and improve investment potential. In this vein, a new tourism strategy was prepared for Redland Shire in early 2003 (ATS Consulting Solutions, 2003). The planning process itself took just three months and sought to be collaborative and inclusive with over 90 participants representing over 50 agencies involved in the process. Collaboration took a number of forms including public forums, questionnaires, stakeholder workshops, interviews and collaborative meetings (ATS Consulting Solutions, 2003: 8). Many of the whirlpools of interests that contributed to the strategy's development have been established for many years, and in some cases, decades. Some have seen several tourism plans be produced over the years and have been involved with other council planning exercises. For example, at the same time that the tourism plan was being produced, the Council was preparing a new statutory planning scheme under the requirements of the Integrated Planning Act 1997. This involved a major shift in the way that planning is undertaken at the local government level, and included a visioning exercise and considerable community consultation across both communities of interests and location. 
At its general meeting on Wednesday 25 July 2003, Redland Shire Council voted 8-3 not to adopt the newly prepared Sustainable Tourism Development Strategy, opting to 'note it' instead. A range of other tourism and recreation studies and strategies conducted over the last 10 years preceded this latest strategy. The existence of these strategies and studies indicates a depth and breadth of information and knowledge about tourism both within the Shire and in its regional context that has been built up over a number of years. Council's decision not to adopt the Sustainable Tourism Development Strategy, despite what might be perceived as a historical commitment to developing a policy position, reflects the vexed and politically charged environment in which tourism planning takes place. Interrelations between networks were significant in this outcome.

Issues were complex and can be summarised in the following:

(1) The division of roles and responsibilities of Council and Redlands Tourism (the membership-based Local Tourism Association [LTA]) were unclear. Council traditionally provided an operating grant for the running of the visitor information centres and the marketing of the Shire's tourism attractions. Addressing membership concerns, Redlands Tourism had become actively involved in planning and policy development activities associated with the management of tourism on NSI. Council saw this as a usurping of its responsibility by Redlands Tourism. As a result, the institutional space in which tourism planning occurred was contested.

(2) The mechanisms for funding the local destination marketing organisation were contentious issues exacerbated by deteriorating relations between Council and Redlands Tourism (ATS Consulting Services, 2003: 122). Redlands Tourism, a membership-based organisation with most of its members based on the Island, had been accused of focusing marketing activities too heavily on NSI to the detriment of mainland areas that had a weaker and less developed product. As one member put it:

... a more representative body should be formed that fairly represents all of the tourism industry throughout the Shire, not just the small slice that happens to be members ... [Redlands Tourism is] an essentially private run company using a large slice of ratepayer's funds and [it] only promot[es] a percentage of the Shire's tourism operators. ${ }^{1}$ (ATS Consulting Solutions, 2003: 10)

(3) On the grounds of compliance with the National Competition Policy, Council decided to cut and then later fully withdraw funding from Redlands Tourism, which had received non-competitive support for over 10 years without the issue being raised. Progression of present and future marketing initiatives by Redlands Tourism, now reliant on membership fees alone, were of considerable concern for operators and drew criticism of the Council.

(4) The Redland Shire community was deeply divided along spatial issues. For example, on Coochiemudlo Island, another Moreton Bay Island, and NSI there were heated debates over acceptable levels of tourism development, visitor, traffic and environmental management (e.g. Cooper, 2003; 
Heffernan, 2003). While these groups engaged in colourful dialogues in the media and on radio, other mainland interests were unable to garner a voice in the debate (ATS Consulting Services, 2003).

(5) The Shire was geographically diverse and varying levels of product development meant that it did not have an immediately identifiable tourism image. The mainland products were based on daytripping; the island's were based on tourism. This diversity made it difficult to achieve a collaborative and collective vision for the Shire's tourism product development.

(6) Diverse levels of sophistication among operators meant that there was a considerable difference in their capacity to collaborate and their ability to be heard. Small family run businesses predominated.

Against this background, the following discussion examines the characteristics of issue networks and policy communities, the nature of the institutional space, inclusion and exclusionary practices of the networks, collaboration and non-collaboration and the nature and effects of sites of difference. As an exploratory study, this paper explores the relevance of these factors to the development of the Redland Shire Sustainable Tourism Strategy. This discussion should be read in conjunction with Figure 3, which summarises the findings and illustrates their relevance to earlier theoretical discussion.

\section{Issue networks and policy communities}

Three broad types of issue networks were highly influential in the discourses underpinning the development of the tourism strategy:

- networks focused on particular issues (e.g. the continuation of Council support for Redland Tourism, growing tourism markets);

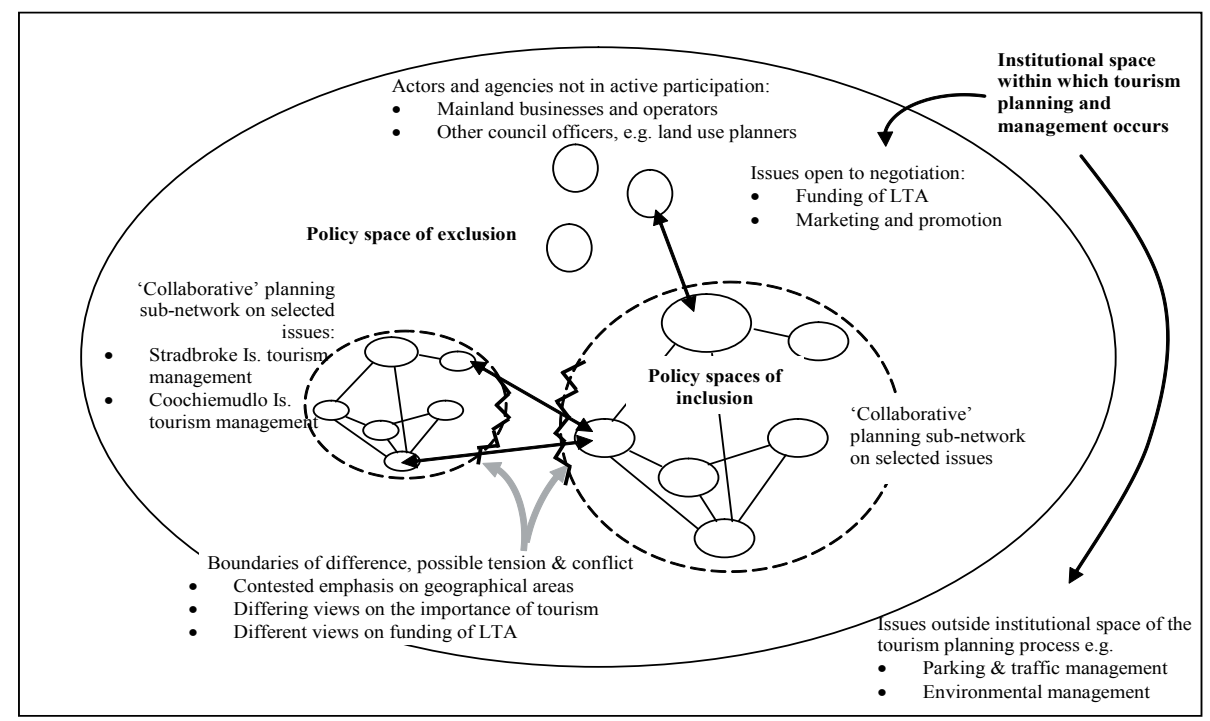

Figure 3 Issue networks and collaborative policy spaces in Redland Shire 
- networks focused on particular geographical locations (e.g. NSI, Coochiemudlo Island, mainland interests); and

- networks focused on the institutional processes (e.g. consultants, Council officers, elected representatives).

These networks overlapped, with many stakeholders participating in more than one network. Some stakeholders, such as the Council, Redland Tourism and the consultants, participated across all networks. While both the Council and Redlands Tourism operate within separate but overlapping issue networks, based principally around planning and product development and marketing respectively, boundaries of conflict and tension arose when roles and responsibilities became entangled and turf sovereignties were disputed.

\section{Institutional space}

The overlapping and conflicting nature of these issue networks suggests a lack of clarity in the roles and responsibilities of Redlands Tourism and Redland Shire Council. There was also a lack of clarity within Council with respect to implementation of the plan. That is, tourism planning necessarily requires an integrated approach across many areas of policy including land use planning, environmental management, infrastructure provision and community servicing and wellbeing. The economic development division of Council commissioned the tourism planning exercise, and, although the process entailed consultation with a wide number of stakeholders, final responsibility for the plan rested with this division. In this sense, the institutional space in which the strategy was prepared was quite narrow, despite embracing the integrated, cross-disciplinary discourse of Ecologically Sustainable Development (ESD). Many of the other Council divisions had no ownership over the plan, no interest in implementation, and no clear statutory or non-statutory directive to do so.

The institutional space in which the collaborative planning exercise was conducted was further clouded because the economic development division had limited means of implementing the strategy and limited means of compelling other sections of Council to do so. The strategy also drew upon a range of voluntary and mixed implementation mechanisms (e.g. environmental accreditation, establishment of a non-membership based peak industry body) over which the economic development division had limited or indirect ability to implement the strategy's recommendations. This lack of institutional clarity in terms of roles and responsibilities for implementation meant that many network actors did not have a strong commitment to the process.

\section{Boundaries of difference}

A myriad of highly focused policy communities operated to influence the tourism planning strategy. These communities might be sector-based, or focused on a particular geographical community of interest. On NSI alone, these policy communities include, for example, FOSI (Friends of Stradbroke Island), SIMO (Stradbroke Island Management Organisation), Amity Point residents group and Quandamooka Lands Council's indigenous interests. Overlapping these networks, the NSI Visioning Committee sought to be an umbrella organisation in striving to develop a coordinated approach for the planning and manage- 
ment of the Island. An active residents' association on Coochiemudlo Island and a range of stakeholder networks across the local government area also sought to raise the profile of particular interests operated independently from the NSI networks. Boundaries of difference therefore existed but were not necessarily characterised by tension.

Other boundaries of difference were characterised by tension. For example, mainland operators were part of a looser issue network that exhibited some tensions with Redlands Tourism and the NSI networks. These tensions were a result of perceived support and emphasis given to NSI interests over mainland interests. The most significant boundary of difference was between Redlands Tourism and the Council. Redlands Tourism sought to undertake marketing, product development and destination planning, and as such came into conflict with the Council who perceived that it was usurping Council's responsibilities in policy development. This boundary was characterised by ongoing tension associated with disputes over roles and responsibilities. The collaborative planning process, while acknowledging that significant differences and tensions existed, did not seek to reconcile differences. Instead a new structure was proposed in which a new, non-membership-based LTA would be established. This new structure assumed that strained historical antecedents could be erased with the establishment of a new association. This did little to reduce tension that had deep historical roots and could not be easily removed through structural change in the networks and institutional arrangements.

\section{Inclusion and exclusion}

Stakeholders are not always clearly defined, nor can interests be easily categorised into themes that facilitate consensus-oriented discussion. In this study, Redland Shire Council was concerned with protecting and enhancing the Shire's present and future tourism potential. It had a generic interest in the economic development of the Shire and in servicing the interests of the Redland Shire population. Redlands Tourism, on the other hand, was a membership-based organisation, and was principally concerned with the interests of its members. The membership focus of Redlands Tourism meant that the network was exclusionary to some extent. However, rules of inclusion and exclusion were open, where non-member operators could integrate into the network by paying a relatively affordable membership fee. Other rules of inclusion and exclusion were based on geographic communities of interest, such as NSI and Coochiemudlo networks, the boundaries of which were more difficult to transcend.

\section{Collaboration and non-collaboration}

In the planning process, stakeholders collaborated on some issues (e.g. marketing initiatives) and conflicted on others (e.g. funding of Redlands Tourism). In this case study, conflict was not always detrimental. Over time conflict can lead to learning and policy entrepreneurialism where, despite adversity, individuals seek common ground on some issues in order to move particular issues forward. The NSI Visioning Committee is an example of the way in which conflict has fostered creativity and learning. The NSI was a geographically focused policy community that emerged from an earlier visioning study. While the community comprised actors and agencies with opposing 
positions, dialogue focused around specific issues enabled the identification of sites of negotiation and compromise.

Our points of view aren't that different. . we all just want what is best for the island. (Bob Hoffman)

It's like a family - we might all fight each other but we always make up in the end. That is what islands are like. (Liz Johnston, Courier Mail 12 July 2003: 33)

\section{Discussion and Conclusion}

This case study firstly sought to identify the potential contributions of network theory to collaborative tourism planning theory through a critical evaluation of the strengths and weaknesses of both streams of literature. The analysis of the literature suggests networks inject a level of political reality into the collaborative planning process which has the potential to be useful in developing a planning process and framework that is more equitable and just. That is, by using a network focus to frame community engagement and collaboration, disempowerment of some interests and groups can be minimised. Equity and justice are important dimensions of sustainable development and networks are a mechanism for further understanding how these play out in the tourism planning process. In other words, networks contribute a messy and dynamic view of tourism planning and embrace the notion that we live in an increasingly networked, shared power world. Embracing and managing this complexity will moves us closer to sustainable development ideals.

The study of tourism planning, framed around the concepts of policy networks and policy communities, also brings into sharper focus the notion that there are sites of collaboration and negotiation in a planning process, but there are also issues on which collaboration and negotiation are not possible. Moreover, boundaries of difference exist between networks and these can be sites of conflict or sites of learning and compromise. The contribution of network theory to collaborative planning theory is, therefore, that networks acknowledge the political nature of collaborative planning. Explicit analysis of these networks in the early stages of the collaborative planning process would provide beneficial knowledge for planners seeking wider and more meaningful engagement with diverse communities of interest over time and geographical space.

The second objective of this paper was to examine how network theory might make a practical contribution to the application of collaborative planning. Clearly, network theory has been subject to much criticism. So has collaborative planning. This paper illustrates that, as a metaphor, and as a lens to understand the dynamics of different destinations, networks have significant merit. This merit is based on the notion that networks help to build complex understandings of dynamic relations over time and space. While this case study was exploratory in nature, further work needs to be done in identifying appropriate methods of inquiry to better understand network interrelations.

The case study suggests that the ideological divide between comprehensive planning processes and incremental policymaking is an important and highly relevant one for vexed planning and policymaking domains such as 
tourism. In the case of Redland Shire, the whole of tourism policy was rejected because various parts were, at the time, politically inappropriate or downright unacceptable. It remains a moot question whether a series of incremental proposals, put to the Council over time, under an adaptive management regime that harnesses opportunities for the temporal engagement of networks as issues move in and out of focus, might be a more appropriate approach.

Based on the foregoing, two lines of further research emerge. Firstly, a valuable line of further investigation in a practical sense would be the development of diagnostic tools that can be used to analyse tourism networks to assist stakeholders to determine boundaries of difference, spaces of inclusion and exclusion and the nature of the institutional space (and a review of those issues that fall within and outside the tourism planning exercise being undertaken). A second line of inquiry is to revisit normative models of tourism planning processes with a view to incorporating and engaging networks of interest. In other words, it is time for planning processes to be conceptualised as exercises of engagement with plural interests, not as a simplistic staged process.

In sum, networks guide inquiry into the social relations that characterise the local organisation of tourism. As a metaphor, networks are open to interpretation and provide opportunities for the researcher to the network metaphor in such a way as to give it meaning in the particular circumstance. While some see this as a weakness (e.g. Dowding, 1995; Klijn et al., 1995), others see this as a creative advantage (Cazal \& Inns, 1998). That is, as a metaphor, networks are imbued with meanings that serve to ignite enquiry and facilitate understanding. Different people interpret networks differently and their flexibility should be viewed as an advantage in facilitating understanding of the political complexities of collaborative planning.

\section{Correspondence}

Any correspondence should be directed to Dr Dianne Dredge, Griffith University, School of Environmental Planning, Nathan, QLD 4111, Australia (D.Dredge@griffith.edu.au).

\section{References}

Atkinson, M. and Coleman, W. (1992) Policy networks, policy communities and the problems of governance. Governance: An International Journal of Policy and Administration 5 (2), 154-80.

ATS Consulting Services (2003a) Redland Shire Sustainable Tourism Development Strategy Background Paper. Cleveland: Redland Shire Council.

ATS Consulting Solutions (2003b) Redland Shire Sustainable Tourism Development Strategy Draft Strategy. Cleveland: Redland Shire Council.

Booher, D. and Innes, J. (2002) Network power in collaborative planning. Journal of Planning Education and Research 21, 221-36.

Borzel, T. (1998) Organizing Babylon: On the different conceptions of policy networks. Public Administration 76, 253-73.

Bramwell, B. (2004) Partnerships, participation and social science research in tourism planning. In A.L Lew, C.M. Hall and A.M. Williams (eds) A Companion to Tourism (pp. 541-54). Oxford: Blackwell.

Bramwell, B. and Lane, B. (eds) (2000) Tourism Collaboration and Partnerships: Politics, Practices and Sustainability. Clevedon: Channel View Publications.

Bramwell, B. and Sharman, A. (1999) Collaboration in local tourism policy-making. Annals of Tourism Research 26 (2), 392-415. 
Braun, P. (2002) Networking tourism SMEs: E-commerce and e-marketing issues in regional Australia. Information Technology and Tourism 5, 13-24.

Burstein, P. (1991) Policy domains: Organisation, culture, and policy outcomes. Annual Review of Sociology 17, 327-50.

Campbell, S. (1996) Green cities, growing cities, just cities? Urban planning and the contradictions of sustainable development. Journal of the American Planning Association 62 (3), 296-312.

Cazal, D. and Inns, D. (1998) Metaphor, language and meaning. In D. Grant, T. Keeney and C. Oswick (eds) Organization and Discourse (pp. 177-92). London: Sage.

Commonwealth Department of Industry, Tourism and Resources (2003) A Medium to Long Term Strategy for Tourism. Canberra: Commonwealth Department of Industry, Tourism and Resources.

Cooper, J. (2003) Tourism is serious business. Redland Times. Cleveland.

Dale, C. (2003) The competitive networks of tourism e-mediaries: New strategies, new advantages. Journal of Vacation Marketing 9 (2), 109-19.

Dowding, K. (1995) Model or metaphor? A critical review of the policy network approach. Political Studies 43 (2), 136-58.

Dredge, D. (2003) Networks, Local Governance and Tourism Policy: Local Tourism Associations Under the Microscope. Coffs Harbour: CAUTHE, Southern Cross University.

Dredge, D. (2006) Policy networks and the local organisation of tourism. Tourism Management 27 (2), 269-80.

Fischer, F. and Forester, J. (1993) The Argumentative Turn in Policy Analysis and Planning. Newbury Park, CA: Sage.

Flyvbjerg, B. (1998) Empowering civil society: Habermas, Foucault and the question of conflict. In M. Douglas and J. Friedmann (eds) Cities for Citizens: Planning and the Rise of Civil Society in a Global Age (pp. 185-211). Chichester: John Wiley.

Forester, J. (1989) Planning in the Face of Power. Berkeley, CA: University of California Press.

Forester, J. (1993) Critical Theory, Public Policy and Planning Practice: Toward a Critical Pragmatism. Albany: State University of New York Press.

Forester, J. (1999) Reflections on the future understanding of planning practice. International Planning Studies 4 (2), 175-93.

Foucault, M. (1976) Two lectures. Critique and Power: Recasting the Foucault-Habermas Debate (pp. 17-46). Cambridge: MIT Press.

Foucault, M. (1980) Power/Knowledge: Selected Interviews and Other Writings (ed. C. Gordon). New York: Harvester Wheatsheaf.

Habermas, J. (1984) Theory of Communicative Action: Reason and the Rationalisation of Society. Boston, MA: Beacon.

Habermas, J. (1987) Philosophical Discourse on Modernity: Twelve Lectures. Cambridge: Polity.

Hall, C.M. (1999) Rethinking collaboration and partnerships: A public policy perspective. Journal of Sustainable Tourism 7 (3\&4), 274-89.

Hall, C.M. and Jenkins, J. (1995) Tourism and Public Policy. London: Routledge.

Halme, M. and Fadeeva, Z. (2000) Small and medium-sized tourism enterprises in sustainable development networks. GMI (Summer), 97-113.

Healey, P. (1997) Collaborative Planning: Shaping Places in Fragmented Societies. London: Macmillan.

Heclo, H. (1978) Issue networks and the executive establishment. In A. King The New American Political System (pp. 87-124). Washington: American Enterprise Institute.

Heffernan, R. (2003) Straddie blue corners locals. Courier Mail (12 July), 33.

Howlett, M. and Ramesh, M. (1995) Studying Public Policy: Policy Cycles and Policy Subsystems. Toronto: Oxford University Press.

Jamal, T. and Getz, D. (1995) Collaboration theory and community tourism planning. Annals of Tourism Research 22, 186-204.

Jamal, T. and Getz, D. (1999) Community roundtables for tourism-related conflicts: The dialectics of consensus and process structures. Journal of Sustainable Tourism 7 (4), 290-313.

Jamal, T., Stein, S.M. and Harper, T.L. (2002) Beyond labels: Pragmatic planning in multistakeholder tourism-environmental conflicts. Journal of Planning Education and Research $22,164-77$. 
Jepson, E.J. (2001) Sustainability and planning: Diverse concepts and close associations. Journal of Planning Literature 15 (4), 499-510.

Klijn, E. (1996) Analyzing and managing policy processes in complex networks: A theoretical examination of the concept of policy network and its problems. Administration and Society 28 (1), 90-119.

Klijn, E., Koppenjan, J. and Termeer, C. (1995) Managing networks in the public sector: A theoretical study of management strategies in policy networks. Public Administration $73,437-54$.

Lovelock, B. (2002) Why it's good to be bad: The role of conflict in contributing towards sustainable tourism in protected areas. Journal of Sustainable Tourism 10 (1), 5-31.

Marsh, D. (1998a) Comparing Policy Networks. Buckingham: Open University Press.

Marsh, D. (1998b) The development of the policy network approach. In D. Marsh (ed.) Comparing Policy Networks (pp. 3-17). Buckingham: Open University Press.

Marsh, D. and Rhodes, R.A.W. (1992) Policy Networks in British Government. Oxford: Clarendon.

McGuirk, P. (2000) Power and policy networks in urban governance: Local government and property led generation in Dublin. Urban Studies 37 (4), 651-72.

Medieros de Araujo, L. and Bramwell, B. (2002) Partnership and regional tourism in Brazil. Annals of Tourism Research 29 (4), 1138-64.

Pal, L. (1997) Beyond Policy Analysis: Public Issue Management in Turbulent Times. Scarborough: Thomson International.

Parsons, W. (1995) Public Policy: An Introduction to the Theory and Practice of Policy Analysis. Aldershot: Edward Elgar.

Pavlovich, K. (2001a) The evolution and transformation of a tourism destination network: The Waitomo Caves, New Zealand. Tourism Management 24, 203-16.

Pavlovich, K. (2001b) The twin landscapes of Waitamo: Tourism network and sustainability through the Landcare Group. Journal of Sustainable Tourism 9 (6), 491-504.

Peters, G. (1998) Policy networks: Myth, metaphor and reality. In D. Marsh (ed.) Comparing Policy Networks (pp. 22-32). Buckingham: Open University Press.

Pforr, C. (2002) The makers and the shakers of tourism policy in the Northern Territory of Australia: A policy network analysis of actors and their relational constellations. Journal of Hospitality and Tourism Management 9 (2), 134-51.

Reed, M. (1997) Power relations and community-based tourism planning. Annals of Tourism Research 24 (3), 566-91.

Rhodes, R.A.W. (1997) Understanding Governance: Policy Networks, Governance, Reflexitivity and Accountability. Buckingham: Open University Press.

Richardson, J. (2000) Government, interest groups and policy change. Political Studies 48, 1006-23.

Sabatier, P.A. (1987) Knowledge, policy-oriented learning, and policy change. Knowledge: Creation, Diffusion and Utilization 8 (4), 649-92.

Sabatier, P.A. (1988) An advocacy coalition framework of policy change and the role of policy-oriented learning therein. Policy Sciences 21, 129-68.

Sabatier, P.A. and Jenkins-Smith, H.C. (1993) Policy Change and Learning: An Advocacy Coalition Approach. Boulder, CA: Westview.

Selin, S. and Beason, K. (1991) Interorganizational relations in tourism. Annals of Tourism Research 18 (4), 639-52.

Shepherd, W. and Liew, L. (2003) Redland: An Economic Profile 2001. Consultants report prepared for Redland Shire Council, Cleveland.

Tinsley, R. and Lynch, P. (2001) Small tourism business networks and destination development. International Journal of Hospitality Management 20 (4), 367-78.

Tremblay, P. (1998) The economic organization of tourism. Annals of Tourism Research 25 (4), 837-57.

Truly Sautter, E. and Leisen, B. (1999) Managing stakeholders: A tourism planning model. Annals of Tourism Research 26 (2), 312-28.

Tyler, D. and Dinan, C. (2001) The role of interest groups in England's emerging tourism policy network. Current Issues in Tourism 4 (2-4), 210-52. 